\title{
NECESSIDADE E PROJETO DE CANTEIRO DE OBRAS EXPERIMENTAL
}

\section{NEED AND DESIGN OF EXPERIMENTAL CONSTRUCTION SITE}

Caroline Bevilacqua Ghedini (1), Fernando Matias Semencio (2), Sibila C. de Arêa Leão Honda (3), Ivair S. Liboni (4), Ivam S. Liboni (4)

Universidade do Oeste Paulista - UNOESTE, cursos de Arquitetura e Urbanismo e Engenharia Civil, Presidente Prudente, SP.

E-mail: sibila@unoeste.br

RESUMO - Os cursos universitários buscam capacitar o aluno de forma que o mesmo, assim que formado, possa ingressar no mercado de trabalho com conhecimentos compatíveis às suas atribuições. Para isso, os conhecimentos teóricos precisam estar associados aos conhecimentos práticos. Vários laboratórios precisam ser disponibilizados para cursos universitários, inclusive para cursos de Arquitetura e Urbanismo e Engenharia Civil, entre eles o canteiro de obras experimental, que insere o aluno no contato direto da obra. No entanto, este ambiente não tem sido implantado com frequência. Desse modo, este artigo visa a analisar sua importância. A metodologia de pesquisa está baseada em análises documentais e projetuais.

Palavras-chave: Arquitetura e Urbanismo; Engenharia Civil; Laboratórios; Aula Prática; Canteiro de Obras Experimental.

ABSTRACT - University courses seek to train the students so that they can enter the job market with knowledge compatible to their responsibilities. For this, theoretical knowledge must be associated with practical knowledge. Several laboratories need to be made available for university courses, including courses for Architecture and Urbanism and Civil Engineering, including the experimental construction site, which inserts the student in direct contact work.

Recebido em: 06/07/2015 Revisado em: 31/07/2015 Aprovado em: 10/08/2015 However, this environment has often not been implanted. Thus, this paper has the objetive to analyze its importance. The methodology of this research is based on documentary and projectual analysis.

Keywords: Architecture and Urbanism; Civil Engineering; Laboratories; Practical Class; Experimental Construction Site. 


\section{INTRODUÇÃO}

Quando os estudantes de Arquitetura e Urbanismo e de Engenharia Civil visam a ir além da prancheta, além do que se vê em livros e estudos teóricos, e o buscam participar de obras, eles criam novas oportunidades a benefício do objeto construído. Neste processo, se estabelece um diálogo mais claro entre os saberes, com troca de informações e aplicações, resulta em conhecimento mais claro sobre como funciona a prática a ser exercida.

No entanto, são poucos os alunos que têm a oportunidade de vivenciar um canteiro e adquirir informações necessárias, pois se o aluno não desenvolve uma visão mais integral do que fará como futuro profissional, poderá vir a cometer equívocos com resultados negativos sociais e ambientais.

O Canteiro Experimental em uma Universidade junto à grade curricular, utilizado de forma correta, vem ser um aliado e garantia no aprendizado prático ao lado do teórico, com a complementação de um ao outro, tornando um método de ensino.

Assim sendo, os cursos de Arquitetura e Urbanismo e Engenharia Civil carecem de mais aulas práticas relativo à vivência em obras, e este artigo visa a auxiliar na discussão teórica sobre canteiros de obras experimentais.

\section{METODOLOGIA}

A metodologia a trabalhada partirá de levantamento de instituições que oferecem cursos de Arquitetura e Urbanismo e Engenharia Civil, e possuem canteiro de obras experimental, identificando os projetos do canteiro. Ao mesmo tempo, a teoria e os conceitos serão aprofundados por meio de artigos científicos e revistas.

\section{DISCUSSÃO}

O motivo principal para a implantação de um canteiro de obras experimental ou canteiro-escola nos cursos de Engenharia Civil e Arquitetura e Urbanismo é que quanto mais experiências práticas os alunos puderem ter e aplicar seus conhecimentos estudados em sala, mais fácil será a concretização do aprendizado teórico, e mais pronto estará para o mercado (SILVA et al., 2009).

O uso da atividade prática deve proporcionar situações reais para o aluno, fazendo com que ele tenha que elaborar e construir conceitos pessoais que sirvam para a situação imposta, provocando o desenvolvimento de novos conhecimentos, uma vez que o novo conhecimento começa a partir do pré-existente. Sua experiência e conhecimento vêm a ficar mais elaborado, a pratica traz mais facilidade no ensino (SILVA et al., 2009). 
Na situação atual, os alunos recebem apenas os conceitos teóricos o que causa uma limitação na prática, desmotivação e insatisfação com relação à falta de conhecimento em campo, e isso acaba se tornando um bloqueio na aprendizagem. E a implantação do canteiro-escola solucionaria os problemas relacionados à falta de atividades que complementem a teoria. Mantendo apenas o teórico se torna uma aula cansativa e sem muita absorção do que se estuda, já vivenciando no real traz mais pontos positivos (SILVA et al., 2009).

Pesquisas mostraram que local com ensino prático e o teórico deixam os alunos mais capacitados para o mercado de trabalho. Já o ensino em conjunto mostrou que alunos nunca utilizaram os conhecimentos adquiridos em sala, eles saem com certo bloqueio por não ter base do funcionamento. Sendo assim relataram que preferem o ensino prático com a vivência real por facilitar a compreensão do material. (SILVA et al., 2009).

O canteiro de obras tem como objetivo propiciar a infraestrutura necessária para produção da obra, com os recursos disponíveis, no momento necessário para sua utilização podendo ser mais eficiente e eficaz em função do projeto do produto e da produção, e da forma de gerenciamento empresarial e operacional, influindo na produtividade da utilização dos recursos, em função da sua organização e do seu arranjo físico (FERREIRA, 1998).

Os projetos das instalações do canteiro dependem do tamanho da obra, do volume de material a serem armazenadas, do número de funcionários, equipes técnicas, dos períodos em que, tanto mão de obra, quanto material deverá estar na obra. (informação apresentada em aula da disciplina de Construção Civil dos cursos Arquitetura e Urbanismo e Engenharia Civil, do Professor Engenheiro Mestre Ivam Salomão Liboni)

O canteiro experimental irá se apoiar na infraestrutura espacial e material tradicionalmente utilizada pelo canteiro de obras, tendo como objetivo a reprodução das técnicas construtivas consolidadas e reconhecidas pela comunidade científica e acadêmica, como também irá se valer de laboratórios de técnicas de construção civil, de materiais e/ou ensaios e/ou práticas de construção (PISANI et al., 2007).

Os canteiros de obras são, inclusive, conceituados em normas técnicas: segundo a NR n.18 (FUNDACENTRO, 1996): “Área de trabalho fixa e temporária, onde se desenvolvem operações de apoio e execução de uma obra." E para a ABNT, por meio da NBR n.1367 (ABNT, 1991): “Áreas destinadas à execução a e apoio dos trabalhos da indústria da construção, dividindo-se em áreas operacionais e áreas de vivência." 
No entanto, bons canteiros devem atender múltiplos objetivos, classificados em de alto e baixo níveis, que, segundo Tommelein, Levitt e Hayes-Roth (1992), alto nível do canteiro estrutura operações seguras e eficientes, além de elevar a moral dos trabalhadores; enquanto o canteiro de baixo nível busca minimizar distâncias e tempo para movimentação de pessoal e material, ampliando a produtividade.

Castro (2011) afirma que a definição de canteiro de obras é uma das partes mais importantes da logística da obra, ou seja, um bom projeto de canteiro auxilia na redução das perdas e otimização da obra. E, para compreensão adequada, há necessidade de familiaridade com o mesmo, visando a futuros projetos de canteiros de obras otimizados. Assim sendo, justifica-se tal pesquisa.

Importante destacar também que o canteiro experimental, segundo 'Perfis da Área \& Padrões de Qualidade' relativo aos cursos de Arquitetura e Urbanismo, o canteiro de obras experimental é fundamental. Gabriel Cunha, docente do curso de Arquitetura e Urbanismo da Universidade Federal da Integração LatinoAmericada (UNILA, 2014) afirma que é um laboratório didático que simula um canteiro de obras convencional. Deve ser composto por um conjunto de ferramentas, equipamentos e materiais de construção, além pessoal técnico especializado, como suporte às atividades de construção que são desenvolvidas pelos alunos.

Segundo Pisani et al. (2007), alguns cursos passaram a incorporar aulas práticas nos canteiros de obras experimentais exercícios como: execução de diversos tipos de alvenarias de tijolos; execução de arcos e abóbadas; revestimentos tradicionais como chapisco, revestimento grosso e fino; assentamento de azulejos e pisos; execução de formas de madeira para concreto armado; amassamento, lançamento, adensamento, cura e ensaios de concretos simples e armados; execução de armaduras de aço para concreto armado; instalações: hidráulica, elétrica e gás; execução de telhados; execução de forros; execução de pinturas e vernizes; execução de fundações moldadas in loco; ensaios com solos; execução de blocos de concreto simples; execução de blocos de solo-cimento; execução de trechos de paredes de pau a pique; execução de trechos de paredes de taipa de mão; execução de protótipos de residências, com as mais diversas técnicas; execução de protótipos e ensaios de materiais e técnicas construtivas com materiais alternativos.

A partir de então, Pisani et al. (2007) informa que ara a montagem de uma canteiro-escola, ou canteiro de obras experimental, são necessários: 
* uma área descoberta ou com pé direito generoso (mínimo de $6 \mathrm{~m}$ ) para os exercícios de grande porte, com áreas que pode variar entre 300 a $10.000 \mathrm{~m} 2$, dependendo da quantidade de alunos matriculados nos cursos oferecidos na instituição;

*os materiais, equipamentos e instrumentos dos laboratórios de materiais e ensaios tecnológicos, maquetaria, conforto ambiental e canteiro de obras, servirão de apoio, portanto, é necessária sua proximidade física e uma gestão integrada;

*necessidade de salas de aula tradicionais que abriguem as aulas teóricas junto ao canteiro experimental.

Importante também que o canteiro experimental esteja integrado com as atividades de pesquisa da graduação, pósgraduação, como também com as atividades de extensão.

\section{CONSIDERAÇÕES FINAIS}

A partir de levantamentos elaborados sobre o que vem a ser um canteiro de obras experimental (ou canteiro experimental, ou canteiro-escola), foi possível compreender melhor o que vem a ser esse espaço de atividades práticas nos cursos de Arquitetura e Urbanismo e Engenharia Civil.

Muitos autores têm discutido sobre o tema. Mas, é bastante relevante o fato de que normas técnicas também tratam do assunto, e que tal ambiente acadêmico está incluído nos 'Perfis da Área \& Padrões de Qualidade' relativo aos cursos de Arquitetura e Urbanismo, sendo fundamental para pesquisas e extensão.

É importante ressaltar a área e o pédireito necessários para estruturação desse ambiente, que inviabiliza um aproveitamento temporário de espaço interno à edificação escolar. Ao mesmo tempo, não deve estar distante da estrutura acadêmica, estimulando a participação dos alunos nas atividades, sejam obrigatórias de ensino, como de pesquisa e extensão.

Ou seja, é um espaço que precisa ser cuidadosamente projetado, focado nas necessidades e estímulos dos discentes, não perdendo o foco do aprofundamento e aperfeiçoamento dos conhecimentos teóricos.

\section{REFERÊNCIAS}

ABNT - ASSOCIAÇÃO BRASILEIRA DE NORMAS TÉCNICAS. NBR n. 1367, 1991. Canteiro de Obras - Diretrizes. Rio de Janeiro: ABNT, 1991.

CASTRO, R.H. Logística aplicada ao canteiro de obras. 2011. Monografia (Graduação) Universidade Federal da Bahia, Salvador BA. Disponível em: $<$ http://rosanalealconsultoria.com/publicaco es/artigo-rodrigo-hipolito.pdf> . Acesso em: 05/04/2015.

FERREIRA, E.A.M. Metodologia para elaboração do projeto do canteiro de obras de edifícios. São Paulo: EPUSP, 1998. Disponível 
$<$ www.pcc.usp.br/files/text/publications/BT_ 00210.pdf>. Acesso em: 05/04/2015.

FUNDACENTRO. NR n.18. Condições e Meio Ambiente de Trabalho na Indústria da Construção. 1996.

PISANI, M.A.J. et al. Canteiro experimental: prática ou invenção?. In: FÓRUM DE PESQUISA FAU/MACKENZIE, 3. Anais... 2007. Disponível em: < http://www.mackenzie.com.br/fileadmin/Grad uacao/FAU/Publicacoes/PDF_IIIForum_a/M ACK_III_FORUM_MARIA_AUGUSTA_2.p df>. Acesso em: 06/07/2016.

SILVA, C.A. et al. A importância da utilização de atividades práticas como estratégia didática para o ensino de ciências. In: EVENTO UFRPE, 2009. Disponível em: < http://www.eventosufrpe.com.br/jepex2009/c d/resumos/r0610-2.pdf $>$. Acesso em: 05/05/2015

TOMMELEIN, I. D.; LEVITT, R. E.; HAYESROTH, B. SightPlan model for site layout. Journal of Construction Engineering and Management, v.118, n.4, p.749-6, dec. 1992. Disponível em: <http://ascelibrary.org/doi/abs/10.1061/\%28 ASCE\%290733-

9364\%281992\%29118\%3A4\%28749\%29?jour nalCode=jcemd4>. Acesso em: 05/05/2015.

UNILA - Universidade Federal da Integração Latino-Americana. Arquitetura e Urbanismo. 2014. Disponível em: <http://unila.edu.br/noticias/arquitetura-eurbanismo-3>. Acesso em: 30/04/2015. 